\title{
Análise de fatores de risco para mortalidade por germes multirresistentes em pacientes internados no Hospital Universitário - Ulbra em Canoas/RS, no ano de 2014
}

\author{
Colato, Marco Antônio Schraiber; Tonello, Gabriele Zuanazzi; \\ Zettler, Eduardo; Machado, Rodrigo Hirsh; Oliveira, Tatiana \\ Schereen de; Lobato, Juliane;
}

\section{RESUMO}

INTRODUÇÃO: durante a prática clínica algumas vezes o médico se depara com um dilema, frente a um paciente provavelmente infectado; ou usa-se um antibiótico de amplo espectro, sob o risco de contribuir para resistência bacteriana e outras reações adversas, ou administra-se antimicrobianos de espectro mais restrito, limitando a chance de acerto terapêutico contra o patógeno infectante. Quando infectados por germes multirresistentes (GMR), os pacientes estão sujeitos a maior morbidade e mortalidade, se comparados a bactérias sensíveis, além de gerar um maior custo à saúde pública.

Método: foram analisados de forma retrospectiva, a totalidade dos pacientes que necessitaram isolamento, indicado pelo Serviço de Controle de Infecção Hospitalar (SCIH), devido a infecção por GMR durante o ano de 2014 no Hospital Universitário (HU) de Canoas, através de pesquisa em prontuário eletrônico.

Resultados: observou-se uma média de idade de 61,3 anos, sendo a sétima década de vida, a faixa etária mais prevalente. As comorbidades mais frequentemente registradas nos prontuários foram hipertensão arterial sistêmica $(45,9 \%)$, diabetes mellitus (27\%), doença neurológica com impacto na qualidade de vida (25\%), tabagismo ativo (21,3\%), doença renal crônica em qualquer estádio (10,6\%), doença pulmonar obstrutiva crônica $(10,2 \%)$ e fibrilação atrial crônica $(9,4 \%)$. Os desfechos finais dos pacientes foram: alta $(57,4 \%)$, óbito $(41 \%)$ ou transferência $(1,6 \%)$, sem diferença estatística entre os sexos. As bactérias mais associadas ao uso de ventilação mecânica foram respectivamente, Acinetobacter sp., Klebsiella pneumoniae, Pseudomonas aeruginosa e MRSA (Staphylococcus aureus 
resistente a meticilina/oxacilina). A taxa de falecimento entre os pacientes que necessitam de UTI foi de $62,5 \%$ e dos submetidos a ventilação mecânica(VM) foi de $67,2 \%$.

Conclusões: podem-se determinar fatores de risco significativamente associados à mortalidade em pacientes com infecções por GMR, que foram: idade acima dos 70 anos, necessidade de UTI, uso de VM, HAS, DRC, DPOC, doença neurológica que impacta na qualidade de vida, hemocultura positiva, aspirado traqueal positivo e infecção pelo Acinetobacter, especialmente da espécie baumanii. Como fatores associados significativamente ao melhor prognóstico, encontramos: idade menor que 40 anos e urocultura positiva. Constatou-se alta frequência de óbitos em pacientes com GMR, muito aquém do ideal. 